\title{
Validation of Near InfraRed preconcentration strategies for ore sorting
}

\author{
S. Iyakwari ${ }^{\mathrm{a}, *}$, H. J. Glass ${ }^{\mathrm{b}}$, G. K. Rollinson ${ }^{\mathrm{b}}$, A. A. Umbugaduc ${ }^{\mathrm{c}}$, O. D. Opaluwa ${ }^{\mathrm{d}}$, B. O. Frankie ${ }^{\mathrm{a}}$ \\ ${ }^{a}$ Department of Geology, Federal University of Lafia \\ ${ }^{b}$ Camborne School of Mines, University of Exeter, Tremough Campus, Penryn, Cornwall, TR10 9FE, UK, \\ ${ }^{c}$ Department of Geology and Mining, Nasarawa State University Keffi, P.M.B. 1022, Keffi \\ ${ }^{d}$ Department of Chemistry, Nasarawa State University, Keffi, PMB 1022, Keffi
}

\begin{abstract}
The early rejection of gangue minerals, at coarse ore particles size (preconcentration), has been shown to be a viable option to cost reduction in many mineral processing applications. A promising technique being explored for efficient ore preconcentration is the Near InfraRed (NIR) spectroscopy. This paper attempts to validate the efficiency of near infrared preconcentration strategies, by comparing data of preconcentrated particles, when particles are scanned using near line scanner from different sides and angle of view. Three copper particles were selected from a batch of sixty preconcentrated samples, mineralogical and near infrared analysis were performed on the particles. Particles were then cut laterally (cross sectioned) and mineralogical and near infrared analysis repeated on the cut cross sectioned surface. Data of the whole samples and crosssectioned samples are compared. Results indicate that the depth attained by scanning (both with NIR and QEMSCAN ${ }^{\circledR}$ ) of original samples is representative of each sample scanned and sufficient for preconcentration. Also, except for the differences in particle size, correlation is almost 1:1, thus, validating the initial NIR preconcentration results as being promising.
\end{abstract}

DOI:10.46481/jnsps.2022.205

Keywords: Preconcentration, Copper ore, Near infrared, QEMSCAN ${ }^{(R)}$, Spectral signature.

Article History :

Received: 29 April 2021

Received in revised form: 04 May 2021

Accepted for publication: 01 September 2021

Published: 28 February 2022

(C)2022 Journal of the Nigerian Society of Physical Sciences. All rights reserved. Communicated by: O. J. Abimbola

\section{Introduction}

Communition and concentration are the two fundamental operations in the minerals processing industries. Communition involves the liberation of ore values, while concentration involves the separation of the liberated ores from their associated gangue minerals [1]. The liberation of ores is achieved through crushing and grinding, the initial size fractions of the run-ofmine while concentration utilizes the various properties of the

${ }^{*}$ Corresponding author tel. no: +2348036347700

Email address: shekwo.i@science.fulafia.edu.ng (S. Iyakwari) ore minerals to achieve separation [2]. For both operations to be efficient, understanding the characteristics of the individual minerals in a given ore is central $[3,4]$.

Grinding accounts for about fifty percent of the total energy used by a concentrator in the mineral processing industries [1]. Considering the high energy requirement of a processing operation, especially grinding, the early rejection of gangue minerals, at coarse ore particles (preconcentration), has been shown to be a viable option to cost reduction in many mineral processing applications [5, 6, 7]. A promising technique 
being explored for efficient ore preconcentration is the Near InfraRed (NIR) spectroscopy [7]. The NIR spectroscopy is a fast, non-invasive and non-destructive technique that provides multi-constituent analysis of virtually any matrix $[8,9]$. It measures the reflective properties of mineral samples without rigorous sample pre-treatment. The NIR covers the wavelength range from the visible $(780 \mathrm{~nm})$ to the mid infrared region $(2526 \mathrm{~nm})[8,10,11]$. The NIR region contains absorption bands corresponding to $\mathrm{C}-\mathrm{H}, \mathrm{O}-\mathrm{H}, \mathrm{S}-\mathrm{H}$ and $\mathrm{N}-\mathrm{H}$ vibrations [12].

This paper attempts to validate the efficiency of the preconcentration strategies and results proposed by Iyakwari et al. [7]. The study presented in this paper, compares data of samples analysed by QEMSCAN ${ }^{(R)}$, and the NIR line scanner. All methods are surface techniques that analyse minerals signatures [7]. Within the NIR region, Iyakwari and Glass [13] classified minerals based on their sensitivity to radiation as; (a) NIR-active, minerals that show absorption features, (b) NIR-active, minerals that do not show absorption features but absorb strongly throughout the longer wavelength region of the NIR and (c) the non-active minerals. With the exception of some high NIR radiation absorbing minerals like hematite [14], only the $-\mathrm{OH}$, $\mathrm{CO}_{3}{ }^{2-}$ and $\mathrm{H}_{2} \mathrm{O}$ functional group bearing minerals are active in the longer wavelength region (1300 to $240 \mathrm{~nm}$ ) used for this research. Hence, comparatively, in the NIR region, the surface NIR-active mineral(s) as detected by QEMSCAN ${ }^{\circledR}$ should be responsible for the NIR absorption observed in the spectra of the samples. This comparison may not be entirely true for all the surface NIR-active minerals, as it has been shown that this may also depend on the depth of particle penetration, which in NIR is defined by the opacity and density of the first NIR-active mineral encountered [4]. Other factors may include angle of scan, the thickness and arrangement of minerals in a particle [13]. Thus this paper investigates the influence of the aforementioned factors on a particle spectrum as well as validating NIR application for ore sorting, as proposed by [7]. Though Iyakwari et al [7] analysed sixty samples, only three representative samples from the batch of 60 are analysed in this paper.

\section{Sample characterization and Method}

Ref. [7] proposed two methods for copper ore preconcentration using the NIR technique. The first strategy targeted both calcite and muscovite/kaolinite feature displaying samples (Figure 1), while the second strategy targeted the elimination of spectra displaying only calcite features as waste (Figure 2).

Three copper samples were selected from a batch of sixty particles preconcentrated by [7]. The particles were originally sampled in a mine in the Loz Pozos mining district in the coastal ranges of the Atacama Region, Northern Chile. The samples were labelled nos. 1, 2 and 3. In [7], same samples are labelled nos. 3, 26 and 53 respectively. Mineralogical and Near InfraRed (NIR) analysis were performed on the same surface for a one to one correlation (Table 1). Hence, each of the 3 particles was subjected to the characterisation process outlined in Figure 3.

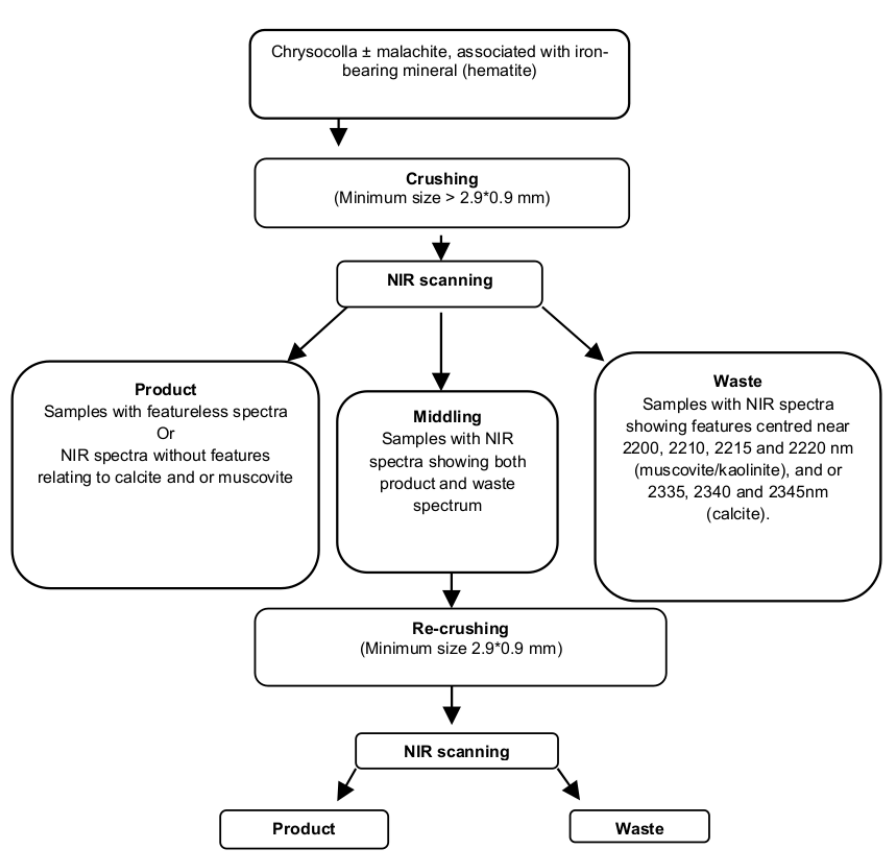

Figure 1: Copper samples preconcentration strategy targeted at discriminating both calcite and muscovite/kaolinite (clay) bearing particles as waste (Iyakwari et al. 2016)

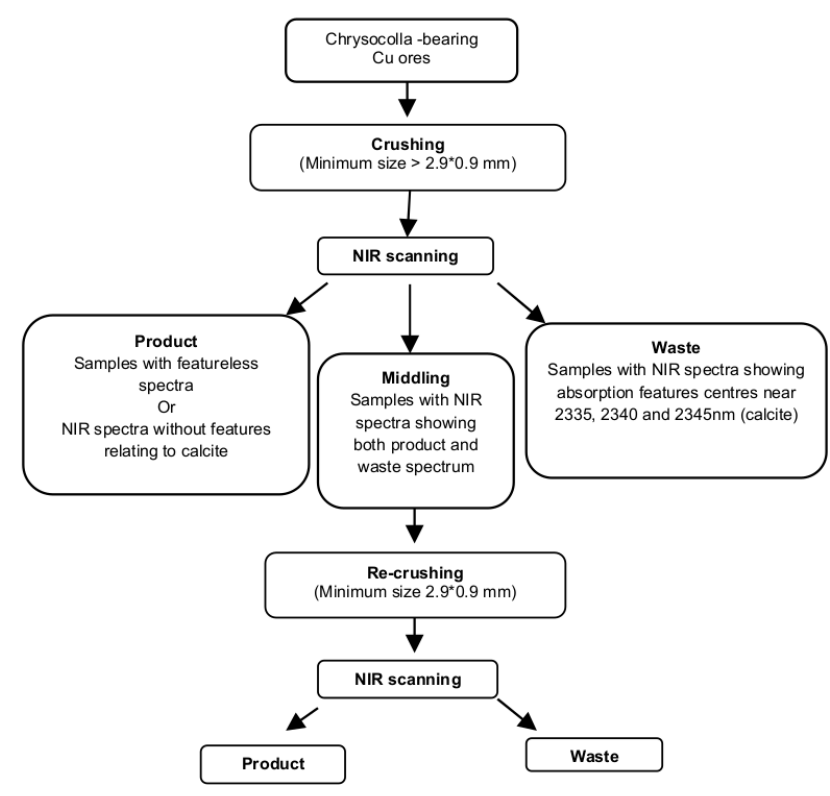

Figure 2: Copper samples preconcentration strategy targeted at eliminating calcite-bearing samples as waste [7] 


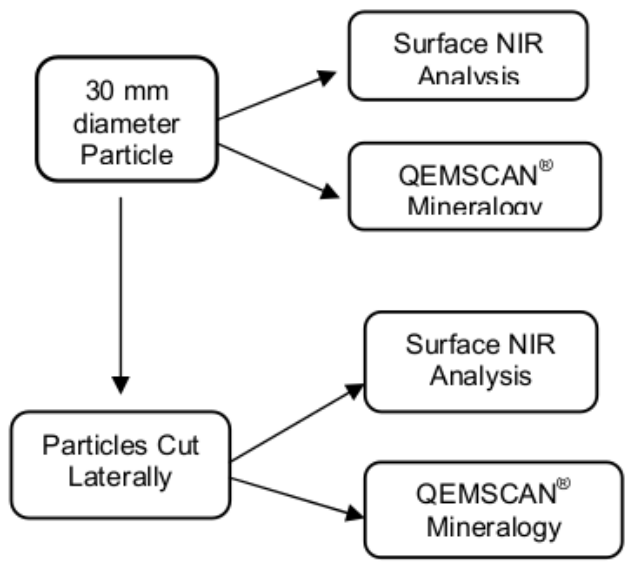

Figure 3: Subdivision of sample particles for characterization

After the initial analysis (Figure 4a), the individual particles were then cut laterally into two halves (Figure $4 \mathrm{~b}$ ) and scanned with both QEMSCAN ${ }^{\circledR}$ and the NIR line scanner. Data of the whole samples and cross-sectioned samples are compared. In the course of subsequent discussion, the issue of particles settling during sample preparation for $\operatorname{QEMSCAN}^{(R)}[15,16]$ is not considered, since samples are cut-slabs and not powdered.

The three particles were mounted into Epofix resin, cut and polished to an even 1 micron finish. The $30 \mathrm{~mm}$ diameter polished blocks (Figure 4a) were marked for orientation and scanned with NIR. After which the polished sample blocks were then carbon coated before scanning with the QEMSCAN ${ }^{\circledR}$. In order to properly map each sample for a 1:1 correlation of NIR and QEMSCAN ${ }^{\circledR}$, individual mounts were demarcated into three sectors measuring $0.9 \mathrm{~cm}$ each, corresponding to the NIR pixel length with a width of $0.29 \mathrm{~cm}$ (Figure 4). By tracking the position of individual spectrum, a precise correlation between the NIR spectra and spatial mineralogical data (fieldscan) from the QEMSCAN ${ }^{\circledR}$ was possible.

From the initial $30 \mathrm{~mm}$ diameter blocks (Figure 2), individual samples were cut into half along their vertical axis (Figure 4b). Samples were then scanned with NIR line scanner after which they were measured with QEMSCAN ${ }^{\circledR}$ using fieldscan mode to allow for a 1:1 correlation with NIR spectra and visual assessment of spatial mineral association as well as provide modal mineralogy.

The mineralogical analysis was performed using the QEMSCAN $^{\circledR} 4300$ system at Camborne School Mines, University of Exeter, UK. Samples were mapped using the fieldscan measurement mode, with a beam stepping interval of $10 \mu \mathrm{m}$. For the original $30 \mathrm{~mm}$ diameter block (Figure 4a) analysis resulted in the acquisition of typically more than 3,500,000 individual X-ray analysis points per sample (i.e. the total number of analysis points, approximately collected per sample, was dependent upon the size/area of the sample as the epoxy resin was ignored). Since the cross sectioned particles are smaller than the original particles, their analysis resulted in the acquisition of about 1,100,000 individual X-ray analysis points per sample, almost one third of the X-ray points obtained from the original particle. The mineral mass data and approximate abundance of copper and other elements were based on the assumed average density of each mineral and back-calculated from the QEMSCAN ${ }^{\circledR}$ primary list, where chemical data was supplied manually. Note that the average density and chemistry values were taken from webmineral.com and can only be used as indicative values $[3,7,16,17]$.

The NIR spectra of samples were measured individually with the NIR line scanner, which acquired spectral data on a succession of adjacent area or pixels across the particle surface. The NIR line scanner consists of an enclosed sample chamber with a cooling facility and three basic components: a conveyor belt, two lamps and a camera. The conveyor belt has a width of $45.6 \mathrm{~cm}$ and a maximum speed of $0.2 \mathrm{~ms}^{-1}$. Data collected for this research is from stationary samples. The belt is illuminated with two Heraeus Noblelight shortwaveinfrared quartz halogen bulbs with gold reflectors (2500 Watt, $480 \mathrm{~V}$ each). The camera is positioned $68 \mathrm{~cm}$ above the conveyor belt, scanning material from right to left, and data is collected along a single transect of 256 pixels. Individual pixels have dimension of 0.29 by $0.9 \mathrm{~cm}$ (Figure 4), with an approximate penetrative depth of $0.7 \mathrm{~cm}$. NIR radiation passing through a narrow slit-shaped opening in the roof of the chamber passes through an imaging spectrometer developed by Tomra Sorting Solutions (www.tomrasorting.com/mining) and Spectra-Map (www.spectra-map.co.uk). The spectrometer allowed selection of wavelength band $( \pm 0.05 \mathrm{~nm})$ at 371 wavelengths between 1308 and $2405 \mathrm{~nm}$. NIR radiation measured at each wavelength is acquired using VIEW 2 software (Tomra Sorting Solutions, www.tomrasorting.com/mining). The measured NIR signal was converted to a reflectance by calibrating the signal by first measuring upper and lower limits. For the upper limit, denoted $I_{\text {light }}$, a highly-reflective board made of aluminium is scanned. For the lower limit, denoted $I_{\text {dark }}$, a scan is made in the absence of near infrared illumination. The near infrared signal, $I$, is now converted into a reflectance, $R$, as follows [18]:

$$
R=\frac{I-I_{\mathrm{dark}}}{I_{\mathrm{light}}-I_{\mathrm{dark}}} .
$$

All spectra were smoothed using OriginPro 9.0 software (OriginLab, Northampton, MA, USA. www.originlab.com) with the Savitzky-Golay method (Savitzky and Golay, 1964). The Savitzky-Golay filter was applied using second order polynomial to a frame size of 9 points. All analyses were performed at the Camborne School of Mines (CSM) laboratory (University of Exeter, UK).

\section{Results and Discussion}

\subsection{Mineralogy}

The QEMSCAN ${ }^{\circledR}$ mineralogical results indicate four major mineral groups: oxides (cuprite, and hematite), carbonates (malachite, calcite and ankerite), silicates (chrysocolla, 


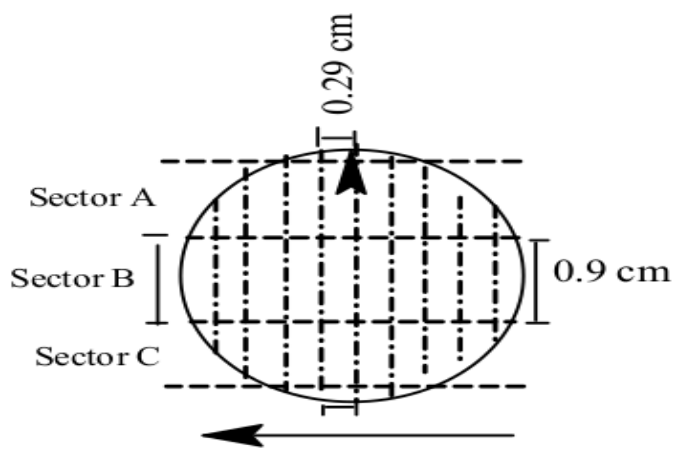

Direction of NIR scan

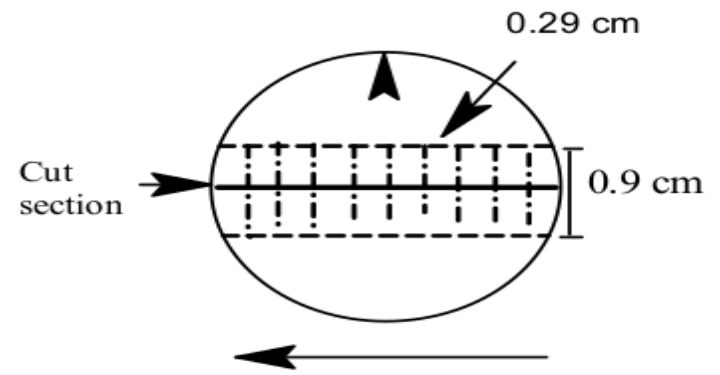

Direction of NIR scan

(a)

(b)

Figure 4: (a) $30 \mathrm{~mm}$ diameter sample marked for spectral and mineral mapping [7] (b) Laterally cut sample marked for spectral and mineral mapping

muscovite, kaolinite, biotite, chlorite, tourmaline, quartz, $\mathrm{k}$-feldspars, and plagioclase feldspars) and traces of phosphate (apatite) as present in the ore (Tables 1, 2, and 3).

Chrysocolla is the most abundant copper bearing mineral in the ore. Malachite and cuprite which are the other copper bearing minerals in the ore only occur as traces (Tables 1,2 and 3). These occurrence is in agreement for both sample types (original $30 \mathrm{~mm}$ diameter block (Table 1) and the cross sectioned samples (Table 3).

Fieldscan images and modal mineral data presented in Tables 1 and 4 shows sample images ranging from the original $30 \mathrm{~mm}$ diameter sections, cross-section, fieldscan images of NIR-active minerals and composite minerals for both sample types. Analysis of the images shows a high degree of mineralogical representativity of the $30 \mathrm{~mm}$ diameter samples in the cross-sections.

Chrysocolla, chlorite, muscovite, calcite and biotite are the feature displaying NIR-active minerals in these ore, while hematite is the only non-feature displaying NIR-active mineral [13]. Hence, mineral data is compared using these NIR-active minerals, for both sample types.

The fieldscan images (Table 4) of cross sectioned samples reveal spatial association between chrysocolla and hematite in sample no.1. Muscovite, chlorite and biotite occur as traces with each having concentrations below 5 wt \%. Both chrysocolla and hematite have concentrations above $10 \mathrm{wt} \%$. Sample no. 2 contains chrysocolla at $3.6 \mathrm{wt} \%$. The sample is low in hematite, with a concentration of $3.8 \mathrm{wt} \%$. Fieldscan images reveal an even spatial occurrence of both chrysocolla and hematite across the sample. Sample no. 3 contains both chrysocolla and hematite below $1 \mathrm{wt} \%$. Calcite is the dominant NIRactive mineral in the sample. The sample's fieldscan images reveal calcite, muscovite and biotite occurring with spatial association as though one mineral lay directly on the other. Same mineralogical association is true for their original $30 \mathrm{~mm}$ diam- eter blocks (Table 4)

\subsection{Near infrared spectra mapping/analysis and implication to ore sorting}

The cross-sectioned spectra are compared with spectra of the original sample measured along sector B (Figure 4a) on the cut face. Due to the shape and smaller size of the cross section of samples nos. 1 and 2 (Tables 1 and 4), only 8, and 7 spectra respectively were obtained compared to 9 and 8 respectively obtained in the original whole samples (Figures $4 a$ and $4 b$ ).

The spectra of sample no. 1 (Figure 5a) appear featureless, the same is observed in the original whole sample (Figure $5 b)$. The appearance of the spectra corresponds to the mineral content as revealed by the modal mineralogy, having dominant hematite and chrysocolla (Table 3). Chrysocolla and hematite occur at ratios 4:6 with both showing spatial association (Table 4). Due to the dominant hematite concentration, the features of chrysocolla are invisible in the spectra. This agrees with findings by [13], who stated that hematite mask chrysocolla diagnostic features even at a ratio of 2:8 (hematite to chrysocolla). Also, the fieldscan image of the samples, Table 4 reveals spatial association of hematite and chrysocolla along sector B of the original sample. The same can be observed on the cross sectioned sample.

The spectra of sample no. 2 show a depression along the longer wavelengths, with the depression lacking an absorption centre (Figure 6a). The samples modal composition shows chlorite (26 wt. \%) as the dominant NIR-active mineral (Table 3). Calcite occurs below the detection limit in the sample. Even at a ratio of 1:9 (hematite to chlorite), hematite is capable of masking the chlorite features normally observed near 1415, 2265 and $2360 \mathrm{~nm}$ [13]. Both spectra (cross sectioned and whole sample) appear similar.

The spectra of sample no.3 (both whole and cross sectioned) show features near 1420, 2215, 2260 and $2345 \mathrm{~nm}$ (Figure 7a and $7 \mathrm{~b}$ ). Individually, these features can be assigned to muscovite $(2215 \mathrm{~nm})$, chlorite $(2260 \mathrm{~nm})$ and calcite $(2345 \mathrm{~nm})$. Therefore, the sample displays a complex spectral mixture. 
Table 1: Samples investigated from the original $30 \mathrm{~mm}$ polished sections, polished cross-sections, combined QEMSCAN ${ }^{\circledR}$ Fieldscan images of NIR-active minerals and composite minerals, in original and crossed sectioned samples respectively

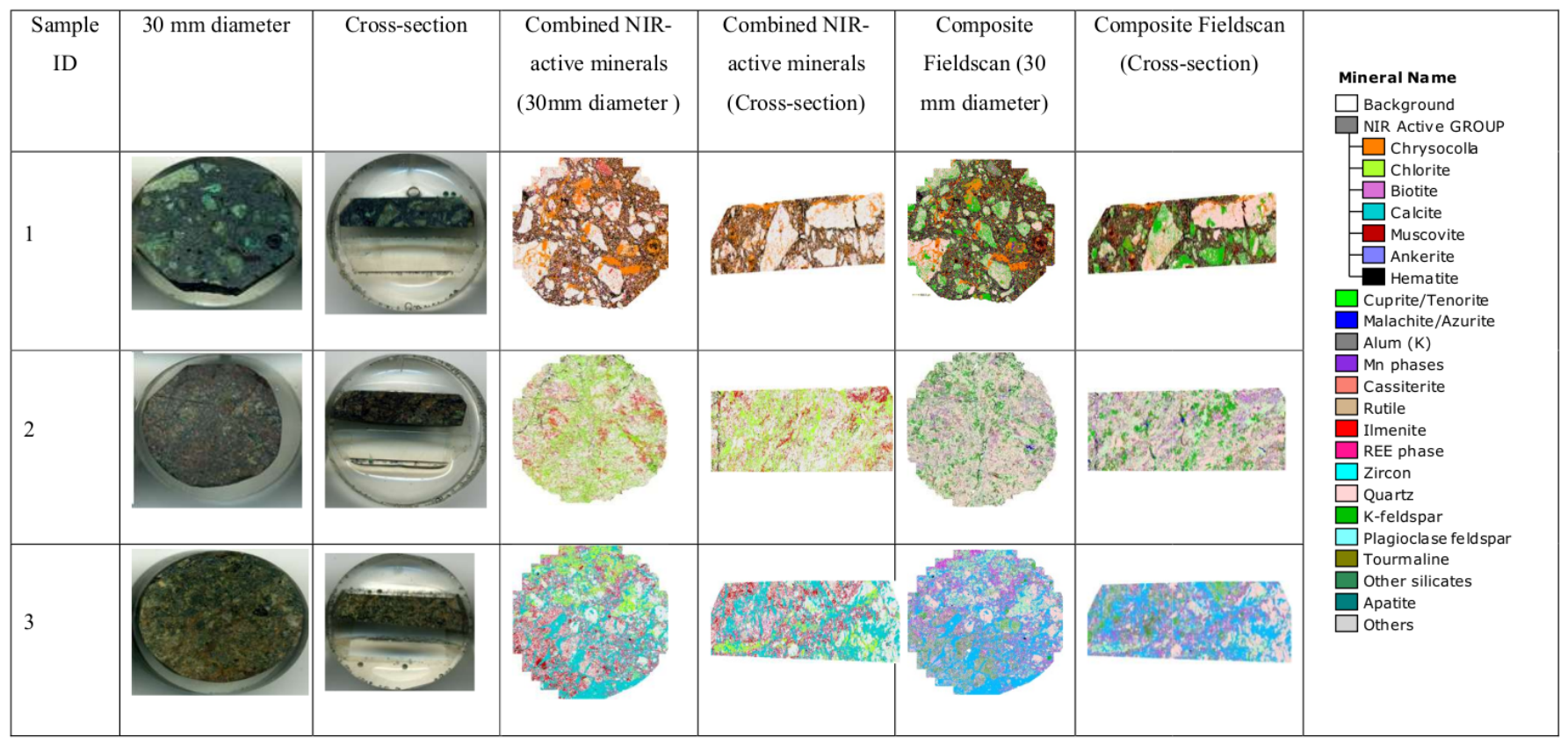

Table 2: Modal mineralogy of the original samples (mass \%) measured by QEMSCAN ${ }^{\circledR},<0.01 \%=$ not detected or below detection limit (Extracted from [7])

\begin{tabular}{|c|c|c|c|c|c|c|c|c|c|c|c|c|c|c|c|}
\hline & \multicolumn{9}{|l|}{ Silicates } & \multirow[t]{2}{*}{ Oxides } & & \multicolumn{3}{|l|}{ Carbonates } & Phosphates \\
\hline & $\begin{array}{l}\text { Cu- } \\
\text { bearing }\end{array}$ & \multicolumn{8}{|c|}{ Non-Cu-bearing } & & Cu-bearir & & \multicolumn{3}{|c|}{ Non-Cu-bearing } \\
\hline & \multicolumn{3}{|c|}{ Non-Iron-bearing } & \multicolumn{3}{|c|}{ Iron-bearing } & \multicolumn{3}{|c|}{ Non-Iron-bearing } & $\begin{array}{l}\text { Iron- } \\
\text { bearing }\end{array}$ & \multicolumn{3}{|c|}{ Non-Iron-bearing } & $\begin{array}{l}\text { Iron- } \\
\text { bearing }\end{array}$ & $\begin{array}{l}\begin{array}{l}\text { Non-Iron- } \\
\text { bearing }\end{array} \\
\end{array}$ \\
\hline & \multicolumn{6}{|l|}{ NIR-active } & \multicolumn{3}{|c|}{ Non-active } & $\begin{array}{l}\text { NIR- } \\
\text { active }\end{array}$ & $\begin{array}{l}\text { Non- } \\
\text { active }\end{array}$ & \multicolumn{4}{|l|}{ NIR-active } \\
\hline $\begin{array}{l}\text { Sample } \\
\text { ID }\end{array}$ & Chrysocolla & Muscovit & Kaolinite & Biotite & Chlorite & Tourmaline & Quartz & K-feldspar & $\begin{array}{l}\text { Plag- } \\
\text { feldspar }\end{array}$ & Hematite & Cuprite & Malachite & Calcite & Ankerite & Apatite \\
\hline 1 & 21.11 & 2.96 & 0.05 & 4.53 & 3.08 & 0.04 & 18.16 & 17.87 & 0.02 & 31.77 & 0.01 & 0.31 & $<0.01$ & $<0.01$ & $<0.01$ \\
\hline 2 & 3.26 & 4.14 & $<0.01$ & 8.47 & 26.35 & 0.4 & 36.34 & 14 & 0.15 & 4.13 & 0.01 & 1.2 & 0.02 & 0.04 & 0.46 \\
\hline 3 & 0.13 & 12.07 & $<0.01$ & 13.61 & 12.14 & 0.53 & 19.18 & 9.42 & 1.14 & 0.39 & $<0.01$ & $<0.01$ & 28.53 & 0.79 & 0.11 \\
\hline
\end{tabular}

Table 3: Modal mineralogy of the cross-sectioned samples (mass \%) measured by QEMSCAN ${ }^{\circledR},<0.01 \%=$ not detected or below detection limit

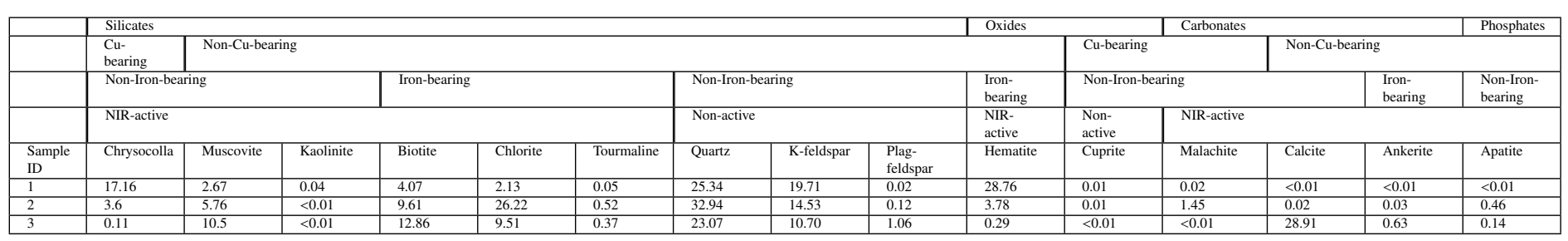


Table 4: NIR-active mineral association mapping of the $30 \mathrm{~mm}$ diameter samples and cross sectioned samples compared

\begin{tabular}{|c|c|c|c|c|c|c|c|c|}
\hline $\begin{array}{c}\text { Sample } \\
\text { ID }\end{array}$ & Chrysocolla & Hematite & Biotite & Muscovite & Chlorite & Calcite & $\begin{array}{l}\text { Combined NIR } \\
\text { Sensitive minerals }\end{array}$ & $\begin{array}{c}\text { Composite } \\
\text { Fieldscan (All } \\
\text { Minerals) }\end{array}$ \\
\hline \multicolumn{9}{|l|}{ no. 1.} \\
\hline & $21.11 \%$ & $31.77 \%$ & $4.53 \%$ & $2.96 \%$ & $3.08 \%$ & $<0.01 \%$ & & \\
\hline \multicolumn{9}{|l|}{$\begin{array}{c}\text { Cross } \\
\text { sectione } \\
\text { d }\end{array}$} \\
\hline & $17.16 \mathrm{wt} \%$ & $28.76 \mathrm{wt} \%$ & $4.07 \mathrm{wt} \%$ & $2.67 \mathrm{wt} \%$ & $2.13 \mathrm{wt} \%$ & $<0.01$ wt $\%$ & Rews & \\
\hline \multicolumn{9}{|l|}{ no. 2 . } \\
\hline & $3.26 \%$ & $4.13 \%$ & $8.47 \%$ & $4.14 \%$ & $26.35 \%$ & $0.02 \%$ & & \\
\hline \multicolumn{9}{|l|}{$\begin{array}{l}\text { Cross } \\
\text { sectione }\end{array}$} \\
\hline & $3.60 \mathrm{wt} \%$ & 3.78 wt $\%$ & $9.61 \mathrm{wt} \%$ & $5.76 \mathrm{wt} \%$ & $26.22 \mathrm{wt} \%$ & $0.02 \mathrm{wt} \%$ & & \\
\hline \multicolumn{9}{|l|}{ no. 3.} \\
\hline & $0.04 \%$ & $0.27 \%$ & $2.24 \%$ & $22.16 \%$ & $1.04 \%$ & $29.68 \%$ & & \\
\hline \multirow{2}{*}{$\begin{array}{c}\text { Cross } \\
\text { sectione } \\
\quad \mathrm{d}\end{array}$} & & & & & & & & \\
\hline & $0.11 \mathrm{wt} \%$ & 0.29 wt $\%$ & $12.86 \mathrm{wt} \%$ & 10.50 wt $\%$ & $9.51 \mathrm{wt} \%$ & $28.91 \mathrm{wt} \%$ & & \\
\hline
\end{tabular}

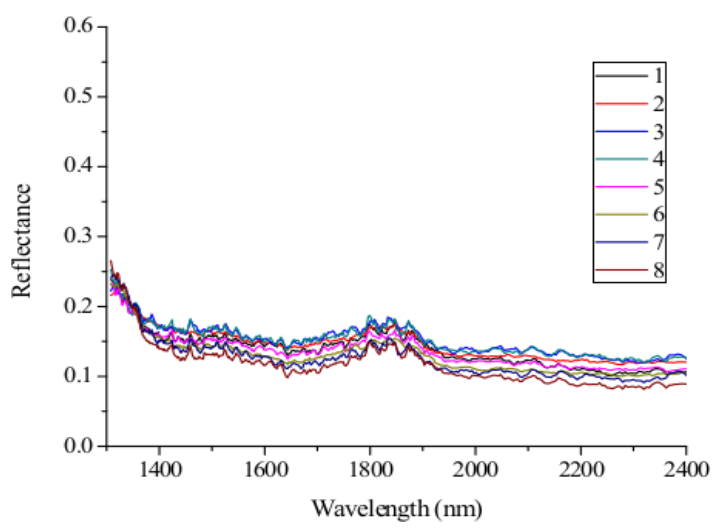

(a)

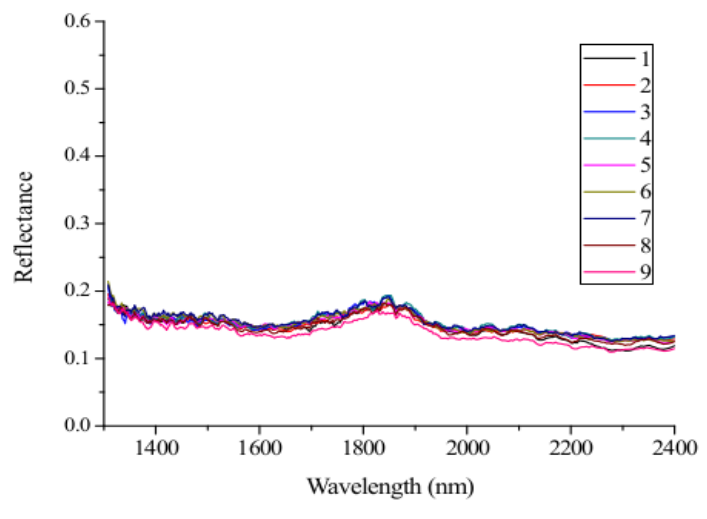

(b)

Figure 5: NIR spectra of sample no. 1 (a) cross-sectioned and (b) whole sample 


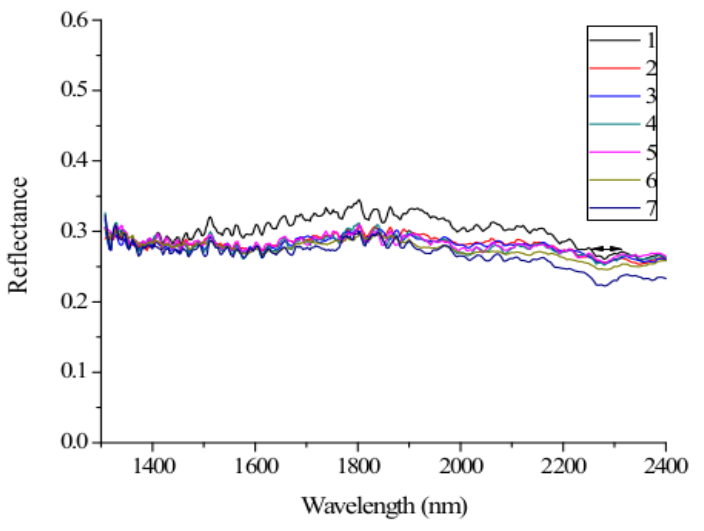

(a)

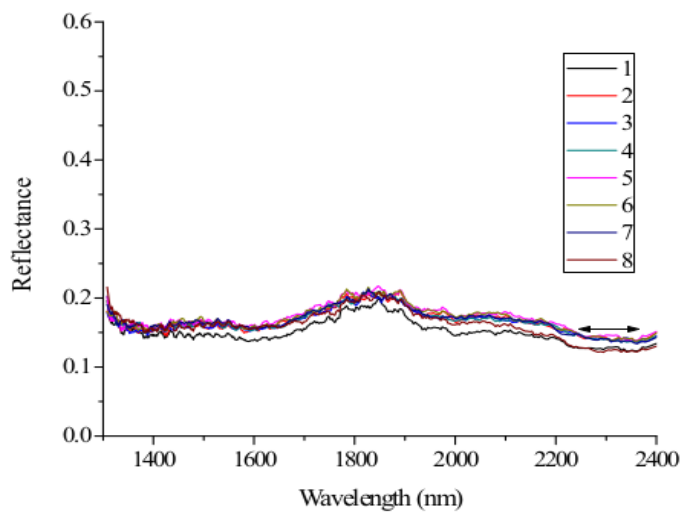

(b)

Figure 6: NIR spectra of sample no. 2 (a) cross sectioned and (b) whole sample

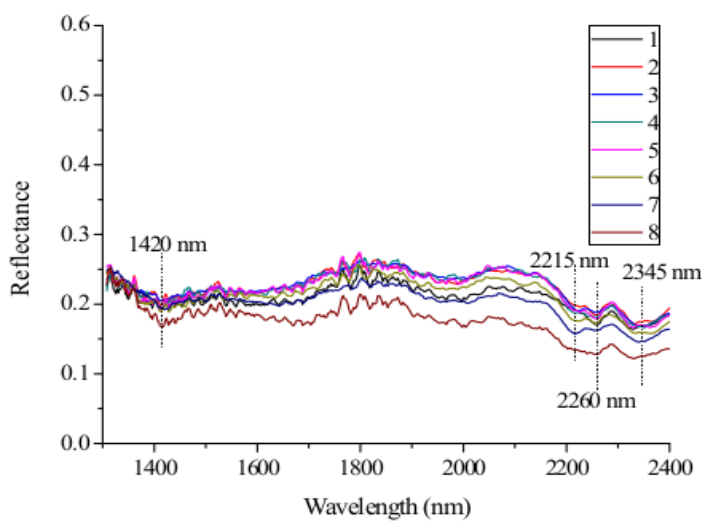

(a)

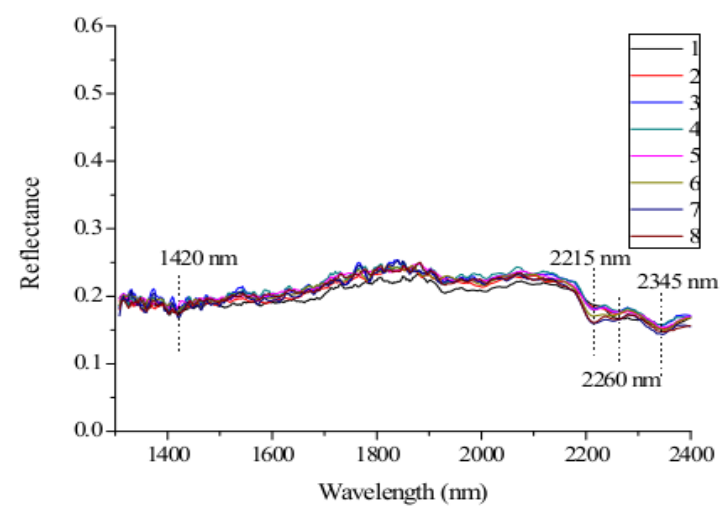

(b)

Figure 7: NIR spectra of sample no. 3 (a) cross-sectioned and (b) whole sample.

Modal mineral data for the cross sectioned samples (Table 3) show muscovite $(10.50 \mathrm{wt} \%)$, chlorite $(9.51 \mathrm{wt} \%)$, and calcite $(28.91 \mathrm{wt} \%)$ as the dominant NIR-active minerals in the sample. Though biotite as one of the NIR-active minerals has a concentration of $12.86 \mathrm{wt} \%$ in the sample, it does not show features in the spectra. The $1420 \mathrm{~nm}$ feature is displayed by both chlorite and muscovite. Hence, the feature is assigned to both minerals. Furthermore, the presence of the $1420 \mathrm{~nm}$ feature indicates that biotite is not strong in the spectra of the sample, as biotite usually occurs with a masked feature near $1400 \mathrm{~nm}$ $[18,20]$.

Hence, with respect to the two classification strategies proposed by [7] (Figures 1 and 2), Samples no. 1 and 2 are products since they lack feature(s) corresponding to either calcite or muscovite, while only sample no. 3 is classified as waste, given it has features corresponding to both muscovite and calcite. Thus, the classification is a repeat of that by [7] on the original whole samples. Considering the second strategy, only sample no. 3 contains and displays calcite features. Hence, similar classification is achieved using the second NIR strategy (Figure 3), where only calcite is considered as waste.

\section{Conclusion}

Spectra of the individual cross sectioned samples compared well with those obtained along sector B of the original whole samples. Thus confirming that analysis is representative and reproducible. The depth attained by scanning (both with NIR and QEMSCAN ${ }^{\circledR}$ ) of original samples is representative of each sample scanned and sufficient for preconcentration. Overall, results indicate that except for the difference in particle size, correlation is almost 1:1. Thus, validating initial NIR preconcentration results.

\section{References}

[1] B. A. Wills, \& T. Napier-Munn, "Mineral processing technology. An introduction to the practical; aspects of ore treatment and mineral", 7th edition Elsevier Sci. \& Tech. Book. (2006) ISBN: 0750644508.

[2] B. A. Wills, "Mineral Processing Technology", Burlington MA, Butterworth-Heinemann (1997).

[3] P. Gottlieb, G. Wilkie, D. Sutherland, E. Ho-Tun, S. Suthers, K. Perera, B. Jenkins S. Spencer, A. Butcher,. \& J. Rayner, "Using quantitative electron microscopy for process mineralogy applications", JOM 52 (2000) 24.

[4] S. Iyakwari, H.J., Glass, \& S.E. Obrike.. Discerning mineral association in the near infrared region for ore sorting. Int. J Miner Process 166 (2017) 24. 
[5] B. Curtis, "Developing automated copper ore processing using NIR analysis and XRD", Adv. Mater. Proc. 170 (2012) 24.

[6] D. J. Bowman, \& R.A. Bearman, "Coarse waste rejection through size based separation”, Miner Eng. 62 (2014) 102.

[7] S. Iyakwari, H.J. Glass G.K. Rollinson \& P.B. Kowalczuk, "Application of near infrared sensors to preconcentration of hydrothermally-formed copper ore", Miner. Eng. 31 (2016) 148.

[8] L. Bokobza, "Near infrared spectroscopy", J Near Spectrosc. 6 (1998) 3.

[9] C. Pasquini, "Near infrared spectroscopy: fundamentals, practical aspects and analytical applications", J. Braz. Chem. Soc. 14 (2003) 198.

[10] R. N. Clark, "Reflectance spectra In: Ahrens, T.J. (Ed.), Rock Physics and Phase: A Handbook of Physical Constants", Washington, American Geophysical Union (1995).

[11] G. Reich, "Near-infrared spectroscopy and imaging: basic principles and pharmaceutical application", Adv. Drug Deliv. Rev. 57 (2005) 1109.

[12] L. Li, Q. Wu, S. Li,. \& O. Wu, "Study of the infrared spectral features of an epoxy curing mechanism", Applied Spectroscopy 62 (2008) 1129.

[13] S. Iyakwari, \& H.J. Glass, "Mineral preconcentration using near infrared sensor-based sorting", Physicochem. Probl. of Miner. Process. 51 (2015) 661.

[14] J. L. Bishop, \& A. Dummel, "The influence of fine-grained hematite powder on the spectral properties of Mars soil analogs; VIS-NIR bidirectional reflectance spectroscopy of mixtures",Lunar and Planetary Institute Science Conference Abstracts 27 (1996).

[15] J. C. O. Andresen, G. K. Rollinson, B. Snook, R. Herrington, \& J.R. Fairhurst, "Use of QEMSCAN for the characterization of Ni-rich and Nipoor goethite in laterite ores", Miner. Eng. 22 (2009) 1119.

[16] K. F. Anderson, F. Wall, G. K. Rollinson, \& C. J. Moon, "Quantitative mineralogical and chemical assessment of the Nkout iron ore deposit, Southern Cameroon", Ore Geol. Rev. 62 (2014) 25.

[17] D. Pirrie, \& G.K. Rollinson, "Unlocking the applications of automated mineral analysis", Geol. Today 27 (2011) 235.

[18] S. Iyakwari, H.J. Glass, \& P.B. Kowalczuk, "Potential for near infrared sensor-based sorting of hydrothermally-formed minerals", J. Near Infrared Spectrosc. 21 (2013) 223.

[19] A. Savitzky, \& M.J. Golay, "Smoothing and differentiation of data by simplified least square procedures", Anal chem. 36 (1964) 1627.

[20] R. N. Clark, G.A. Swayze, R. Wise, K.E. Livo, T.M. Hoefen, R.F. Kokaly, \& S.J. Sutley, S.J., "USGS Digital Spectral Library splib05a”, U.S. Geological Survey, Open File Report (2003) 03. 